\title{
PHLYCTENULAR CONJUNCTIVITIS IN AFRICAN CHILDREN
}

\author{
BY \\ HARRY STEIN and IDA FREIMAN \\ From the Baragwanath Hospital, Johannesburg
}

(RECEIVED FOR PUBLICATION DECEMBER 12, 1957)

Phlyctenular conjunctivitis is a focal inflammatory disease of the conjunctiva characterized by a rounded translucent nodule surrounded by a zone of hyperaemia. The nodule may be single or multiple and is situated on the conjunctiva, close to the corneal limbus. Histologically it is an aggregation of large numbers of lymphocytes and occasional polymorphonuclear cells. Secondary infection, photophobia, blepharospasm and lacrimation are features of this condition.

Phlyctenular conjunctivitis is relatively rare among Europeans, but is still common in nonEuropean communities. In 1947 an American Medical Association investigation committee (Barnett, Fields, Milles, Silverstein and Bernstein, 1947) reported that $20 \%$ to $50 \%$ of children in Alaskan native villages had corneal scars, due to healed phlyctenulosis. Thygeson (1951) noticed a very high incidence of this condition among Apache Indians of Arizona during the years 1934 to 1938 and among the Negro and Puerto Rican children of New York City before World War II.

At Baragwanath Hospital where we deal with an African urban community living under poor hygienic circumstances we see active phlyctenulosis among the children quite commonly. At the Children's Outpatient Department which is attended by children up to 9 years of age, and where the total yearly attendance of new cases is $40,000,36$ active cases of this condition were seen in a 12month period. We were particularly interested in elucidating the relationship of these cases to tuberculosis which is rife in the community.

\section{The Present Study}

This study was done retrospectively and is based on the records of all cases of active phlyctenular conjunctivitis seen at the Children's Outpatient Department in the 12 months from November, 1955, to October, 1956. There were 36 in all.

The age range among our 36 cases was 1 to 9 years, the majority of them being 4 to 8 years old. A slight preponderance of females, 19, to males, 17, was noted, and there appeared to be no month or season in which the cases presented predominantly. The standard of nutrition was average for urban African children in Johannesburg, except for one child who was so malnourished that he was specifically admitted for this.

All of the 36 cases had radiographs of the chest taken. Unfortunately, due to a fear of the excessively strong allergic reactions to tuberculin which have occurred from time to time in this condition, only 17 of the 36 were tested for tuberculin sensitivity, using the tuberculin jelly patch test. Of these 17 cases 15 showed positive reactions, three of which were severe with blistering and tissue necrosis, and two were negative. The radiological survey showed 22 cases with definite evidence of active or healed tuberculosis and of these, five cases had calcified tuberculous lesions (Fig. 1a and b). Fourteen cases had completely normal chest radiographs. One case had associated erythema nodosum and another case had a tuberculide rash.

\section{Discussion}

Price (1948) states that the majority of cases of phlyctenular conjunctivitis occur within the first 5 years of life. In Sorsby's (1942) series the age of maximum liability was from 4 to 10 years. Thygeson's cases occurred most commonly between the ages of 8 to 15 years. Our cases occurred predominantly between 4 and 8 years.

Both Sorsby and Thygeson state that the condition is more common in females. In our cases there was only a slight predominance of females over males. Sorsby noted that this condition presented more commonly in Spring; in our cases there appeared to be no seasonal variation.

Malnutrition, focal sepsis, pediculosis and worm infestation have all been incriminated as aetiological agents from time to time. The findings in this 
series do not support these views. Thygeson states that phlyctenulosis is most frequent in children from the lower economic strata of society whose diet is most likely to be deficient. Our cases all occurred in a predominantly malnourished society, but only one was severely malnourished, the nutrition of the others varying within the average range.

Most writers stress the aetiological importance of tuberculosis, although there is considerable disagreement about the specific phase of tuberculosis with which it is associated.

Sheldon (1955) states that phlyctenular conjunctivitis and erythema nodosum are benign allergic manifestations of primary tubercle occurring

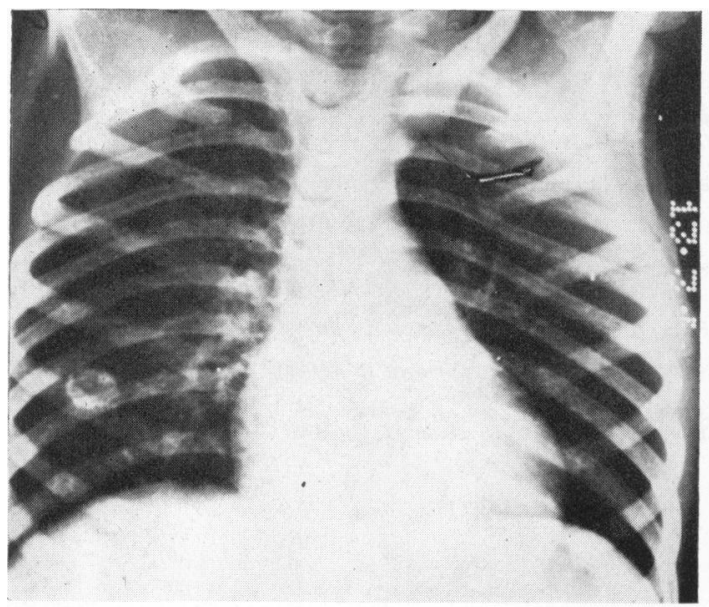

(a) Posterior-anterior view
Ellis (1956) states that as in the case of erythema nodosum, phlyctenular conjunctivitis is regarded as an allergic manifestation for which tuberculous infection elsewhere in the body is responsible in more than $75 \%$ of cases. Whilst non-tuberculous cases may occur and while there appears to be some relationship with malnutrition, it should always be assumed that tuberculosis is an aetiological factor until investigation has proved otherwise.

When Fritz and Thygeson (1951) investigated phlyctenular conjunctivitis in Alaskan Indians and Eskimos they found that all cases of active phlyctenulosis had positive tuberculin reactions, while radiographic evidence of active or inactive pulmonary tuberculosis in a comparative study of two

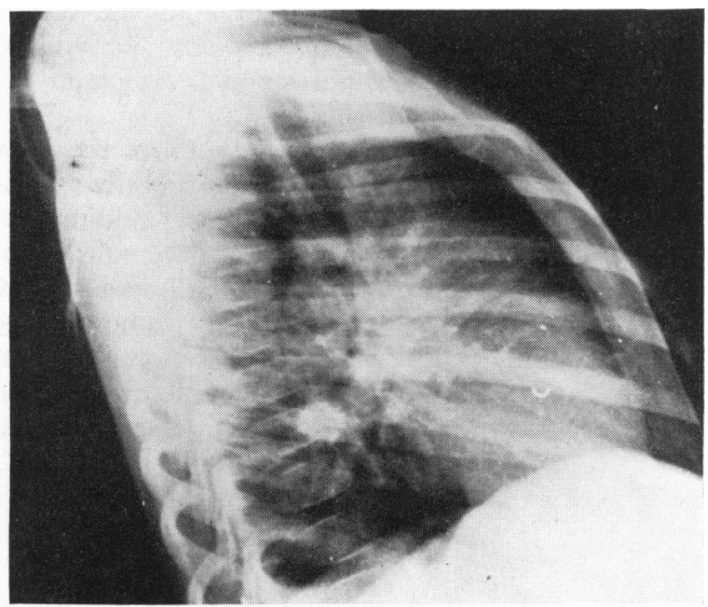

(b) Lateral view.

FIG. $1(a)$ and $(b)$.-Chest radiographs showing calcified primary focus in lungs of patient with phlyctenular conjunctivitis.

at the time of Mantoux conversion and that their presence indicates early tuberculosis. Holt and McIntosh (1940) state that phlyctenular conjunctivitis may occur at the height of the initial tuberculous infection but that it is more common later and shows a tendency to recurrence and chronicity; they also state that it is invariably a manifestation of tuberculosis and is accompanied by a high degree of allergy. Lightwood and Court (1953) claim that, although there is clearly a relationship between tuberculosis and phlyctenular conjunctivitis, the oft-repeated statement that phlyctenulosis is strictly analogous to erythema nodosum is not true and its onset bears no fixed relationship to the emergence of primary tuberculous allergy; they feel that it is best considered as a response to sensitization by several allergens of which in Great Britain tuberculosis is the most important.
Alaskan villages showed a parallel between the prevalence of tuberculosis and phlyctenular conjunctivitis.

Sorsby (1942) writing on phlyctenular conjunctivitis in children and adolescents in England, found that in 592 cases $84.8 \%$ were tuberculin positive, as against $15.3 \%$ in 900 control cases, and that of 510 cases examined radiologically $72 \cdot 2 \%$ showed evidence of pulmonary tubercle as against $16 \cdot 1 \%$ positive radiographs in 87 controls. The same author investigating the family history of tuberculosis found an incidence of $28.9 \%$ in 263 school children with phlyctenular conjunctivitis as opposed to an incidence in the normal school population of $3 \cdot 7 \%$. The expectation of subsequent overt tuberculosis was statistically higher in the phlyctenular conjunctivitis group.

Damato (1951) reports the cases of 11 children in 
Malta who developed phlyctenular conjunctivitis two to six weeks after BCG vaccination and he concludes that this is evidence that phlyctenular conjunctivitis is due to sensitization with tuberculoprotein. He also attributes the lowered general incidence of phlyctenulosis in Malta in recent years to the lowered incidence of tuberculosis brought about by BCG innoculation.

Fritz and Thygeson (1951) consider that phlyctenular conjunctivitis in well-developed tuberculosis may be due either to activation of an already existing focus of tuberculosis which liberates antigenic products into the blood stream or to nonspecific vasodilatation caused by secondary bacterial infections of the eye bringing circulating tuberculous antigens to the conjunctivae. They have repeatedly observed the effect of epidemic KochWeeks bacillus and pneumococcal conjunctivitis in exciting acute attacks of phlyctenular conjunctivitis in susceptible children.

Our series of cases appears to confirm the view that phlyctenular conjunctivitis is commonly associated with tuberculosis. An interesting finding was that of associated long-standing tuberculous infection as evidenced by calcified lung lesions in five patients. As far as we could determine all the patients were suffering from phlyctenular conjunctivitis for the first time since there was no evidence of old scarring. This suggests that although there is a link between phlyctenular conjunctivitis and tuberculosis, the condition is not necessarily associated with the early hyper-allergic phase of tuberculosis occurring at the time of Mantoux conversion, i.e. approximately six weeks after the initial infection. We feel that this supports the view that phlyctenulosis is not analogous to erythema nodosum and that its appearance bears no fixed relationship to the onset of primary tuberculous allergy.

We wish to thank Dr. E. Kahn (Senior Paediatrician) and Dr. S. Wayburne (Paediatrician) for help in the preparation of this paper, and the Medical Superintendent of Baragwanath Hospital for permission to publish these records. We would also like to thank Dr. M. H. Shnier for the photographs.

REFERENCES

Barnett, H. E., Fields, J., Milles, G., Silverstein, J. and Bernstein, A. (1947). J.Amer. med. Ass., 135, 500.

Damato, F. J. (1951). Brit. J. Ophthal., 35, 416

Ellis, R. W. B. (1956). Diseases in Infancy and Childhood, 2nd ed. p. 532. Edinburgh.

Fritz, M. H. and Thygeson, P. (1951). Publ. Hlth Rep. (Wash.), 66, 934.

Holt, L. E. and McIntosh, R. (1940). Holt's Diseases of Infancy and Childhood, 11 th ed., p. 333. New York.

Lightwood, R. and Court, D. (1953). In Garrod, Batten and Thursfield's Diseases of Children, 5th ed., Vol. 1, p. 804 Thursfield's Diseases of Children, 5th ed., Vol. 1, p. 804.
Edited by A. Moncrieff and P. Evans. London.

Price, D. S. (1948). Tuberculosis in Childhood, 2nd ed., p. 186. Bristol.

Sheldon, W. (1955). Diseases of Infancy and Childhood, 7th ed., p. 402. London.

Sorsby, A. (1942). Brit. J. Ophthal., 26, 159.

Thygeson, P. (1951). Amer. J. Ophthal. 34, 1217. 